\title{
PKP/PVP combine chemotherapy in the treatment of multiple myeloma patients with vertebral pathological fractures: minimum 3-year follow-up of 108 cases
}

Xingchen $\mathrm{YaO}^{\dagger}$, Ziyu $\mathrm{Xu}^{\dagger}$ and Xinru Du*

\begin{abstract}
Background: Multiple myeloma (MM) is a blood system malignant tumor, which often leads to osteolytic bone destruction, and the vertebral column is the primary site of involvement. However, the efficacy and prognosis of percutaneous kyphoplasty/vertebroplasty (PKP/PVP) for simple vertebral pathological fractures in patients with multiple myeloma are not yet unified. The primary objective of this study was to investigate the efficacy and prognosis of PKP/PVP in the treatment of multiple myeloma patients with vertebral pathological fractures.
\end{abstract}

Methods: A total of 108 patients with MM from Beijing Chao-Yang Hospital from 2007 to 2013 were enrolled. Of these, 52 patients underwent PKP/PVP surgery and chemotherapy (surgery group) and 56 received only chemotherapy (chemotherapy group). The age, gender, International Staging System (ISS), fracture location, segment, visual analog scale (VAS), Oswestry Disability Index (ODI), comprehensive treatment satisfaction, stem cell transplantation, overall survival (OS), mortality rate, and the cause of death of patients were recorded; the mean follow-up time was 42.46 months.

Results: The average age of patients in surgery and chemotherapy groups was 60.8 years and 58.1 years, and the mean survival time was 41.98 months and 43.30 months, respectively. The VAS score at 1 month and last follow-up after treatment in surgery group were significantly lower than those in the chemotherapy group $(P<0.05)$; the ODI at 1 month after treatment in the surgery group was significantly lower than that in the chemotherapy group $(P<0.05)$; no significant difference was observed in the 3-year mortality rate between surgery and chemotherapy groups. The number of patients who developed activity disorder in the surgery group was significantly less than that in the chemotherapy group $(P<0.05)$. The OS of patients in ISS stage III was significantly less than that in ISS stages I and II $(P<0.05)$.

Conclusions: PKP/PVP surgery can greatly relieve the pain caused by fractures, reduce the risk of being completely bedridden and pulmonary infection, and improve the quality of life of patients; however, it did not affect mortality rate and overall survival time in patients.

Trial registration: As this was a retrospective study, it did not require ethical approval; all patients had signed informed consent when they received treatment, and all treatment options were voluntary.

Keywords: Multiple myeloma, Percutaneous kyphoplasty, Prognosis, Spine

\footnotetext{
* Correspondence: duxinru@163.com

${ }^{+}$Xingchen Yao and Ziyu Xu contributed equally to this work.

Department of Orthopaedics, Beijing Chao-Yang Hospital, Capital Medical

University, No.8 Gongren Tiyuguan Nanlu, Chaoyang district, Beijing, China
}

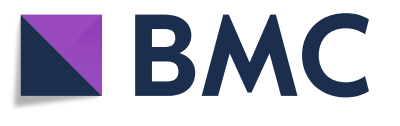

(C) The Author(s). 2019 Open Access This article is distributed under the terms of the Creative Commons Attribution 4.0 International License (http://creativecommons.org/licenses/by/4.0/), which permits unrestricted use, distribution, and reproduction in any medium, provided you give appropriate credit to the original author(s) and the source, provide a link to the Creative Commons license, and indicate if changes were made. The Creative Commons Public Domain Dedication waiver (http://creativecommons.org/publicdomain/zero/1.0/) applies to the data made available in this article, unless otherwise stated. 


\section{Background}

Multiple myeloma (MM) is a blood system malignant tumor, which often leads to osteolytic bone destruction, and the vertebral column is the primary site of metastasis [1]. With the development of disease, some patients may suffer from pathological fracture or neurological dysfunction. Thus, surgery was used to stabilize the vertebral column and improve the neurological dysfunction. When MM patients have pathological vertebral fractures but no neurological symptoms and intraspinal space occupancy, minimally invasive surgery can be performed, such as percutaneous kyphoplasty (PKP) and percutaneous vertebroplasty (PVP) [2]. Some researchers found that $\mathrm{PKP} / \mathrm{PVP}$ for pathological vertebral fractures in MM patients can effectively relieve symptoms in the short term without serious consequences [3]. Some scholars took a wait-and-see attitude, who held that only treatment with chemotherapy also can relieve pain in some MM patients, but surgery may lead to the risk of recurrent fractures of adjacent vertebrae [4].

Our previous studies have shown that although the bone cement leakage rate in MM patients is higher than that in osteoporotic vertebral compression fractures, no serious complications such as neurological impairment, pulmonary embolism, and short-term adjacent vertebral fractures have occurred [5]. Although some retrospective studies have initially explored the efficacy and prognosis of minimally invasive surgery for MM pathological vertebral fractures in recent years, these studies have to some extent been inadequate, such as fewer cases included and shorter follow-up time. Thus, the benefits of minimally invasive surgery for $\mathrm{MM}$ patients remain to be further studied.

In this retrospective study, a 3-year follow-up study was conducted to review the patients with MM treated at the Beijing Chao-Yang Hospital, Beijing, China. We analyzed the visual analog scale (VAS), Oswestry Disability Index (ODI), postoperative activities, comprehensive treatment satisfaction, and other clinical indicators to explore the efficacy and prognosis of minimally invasive surgery for multiple myeloma complicated with pathological vertebral fractures.

\section{Methods}

\section{General information}

A total of 108 patients with MM treated at our hospital from 2007 to 2013 were enrolled. The pathological fracture of the vertebral column was diagnosed based on the $\mathrm{X}$-ray, CT, and MRI, and the location and number of fractures were determined. All patients were $>18$ years of age and had lumbar back pain without neurological symptoms. A total of 52 patients underwent PKP/PVP and chemotherapy (surgery group) (Fig. 1), and 56 patients received chemotherapy alone (chemotherapy group). The surgery group involved a total of 86 vertebrae, of which 37 were thoracic vertebrae and 49 were lumbar vertebrae. The chemotherapy group involved a total of 112 vertebrae, of which 2 were cervical vertebrae, 59 were thoracic vertebrae, and 51 were lumbar vertebrae. The age, gender, International Staging System (ISS), fracture location, segment, VAS, ODI, comprehensive treatment satisfaction, stem cell transplantation,

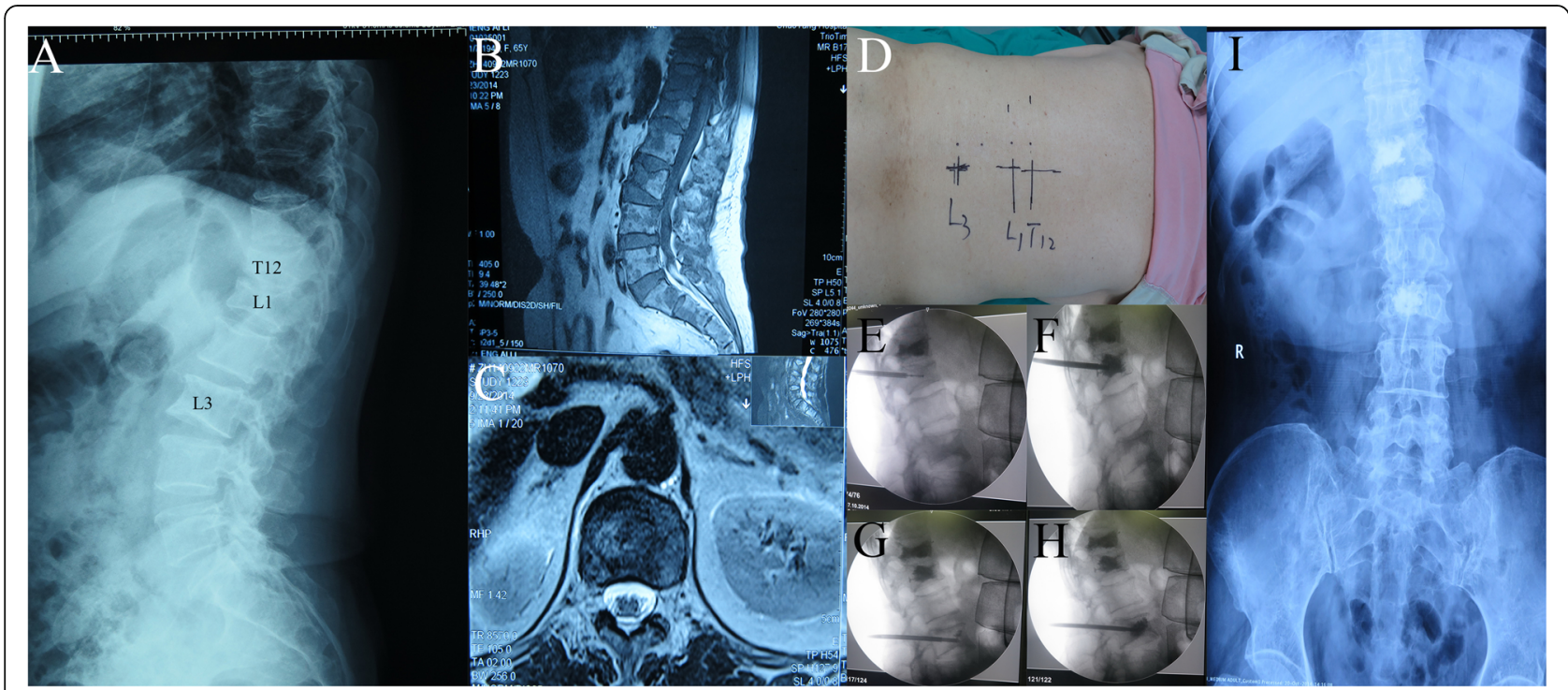

Fig. 1 Images from one patient from the surgery group. a-c Patient with multiple myeloma with a pathological fracture of T12/L1/L3. $\mathbf{d}-\mathbf{h}$ Patient was placed in the prone position, and the location of the lesion was determined by X-ray using a C-arm and marked. The filling of the vertebral body with bone cement was monitored. Image obtained during surgery. i A postoperative X-ray plain film scan indicated that the bone cement was implanted successfully. Image obtained following surgery 
overall survival (OS), mortality rate (1, 2, and 3 years), and the cause of death of patients were analyzed statistically. ISS stage I was defined as serum $\beta 2$-microglobulin levels $\leq 3.5 \mathrm{mg} / \mathrm{L}$ and serum albumin levels $\geq 3.5 \mathrm{~g} / \mathrm{dL}$. ISS stage II included all patients with neither stage I nor stage III disease. ISS stage III was defined as serum $\beta 2$-microglobulin levels $\geq 5.5 \mathrm{mg} / \mathrm{L}$, irrespective of serum albumin levels [6]. Among these parameters, ISS staging was often used to assess the tumor load and prognosis of patients, which was regarded as a major risk factor affecting the survival time in patients with MM $[7,8]$. Therefore, in this study, ISS staging was selected as the staging standard for statistical analysis.

Herein, the VAS, ODI, and incidence rate of pain-related activity disorders were observed before and after treatment in order to assess the quality of life. Comprehensive treatment satisfaction was used to evaluate patients' satisfaction with treatment effects. Moreover, the prognosis of patients was assessed by the OS, 3 -year mortality rate, and the cause of death of patients in each group. After the patients were divided into groups according to the ISS staging, the quantity and location of fractures, as well as the efficacy of PKP/PVP in patients with MM, were evaluated by various methods.

\section{Statistical methods}

Patients' clinical symptoms and data before and after the treatment were analyzed by chi-square test and independent sample $t$-test. The risk factors that might affect the OS in patients were analyzed by Cox model analysis (univariate analysis and multivariate analysis). The survival time was assessed by the Kaplan-Meier method and examined by the log-rank test. All data were analyzed by SPSS 23.0 statistical software. The measurement data were expressed as mean \pm standard deviation, and $P<0.05$ was considered as significant difference.

\section{Results}

A total of 108 patients in the two groups were analyzed by a single factor method (Table 1$)$. Surgery group comprised of 23 males (44.2\%) and 29 females (55.8\%), with an average age of 61.81 years (SD: 8.841), and 9 patients received stem cell transplantation (17.3\%). The chemotherapy group consisted of 31 males $(55.4 \%)$ and $25 \mathrm{fe}-$ males (44.6\%), the average age was 58.14 years (SD 8.225), and 18 patients underwent stem cell transplants (32.1\%). Furthermore, no statistical difference was observed in ISS staging, and the quantity and location of fractures between the two groups; the mean follow-up time was 42.5 months. The VAS score at 1 month and last follow-up after treatment in the surgery group were significantly lower than those in the chemotherapy group $(2.65 \pm 0.683$ and $3.27 \pm 0.744$ vs. $3.55 \pm 0.893$ and $4.77 \pm 1.279)(P<0.001)$ (Fig. 2$)$. The ODI at 1 month after treatment in the surgery group was significantly lower than that in the chemotherapy group $(0.19 \pm 0.072$ vs. $0.29 \pm 0.116)(P<0.05)$. However, there was no significant difference in the ODI between the two groups at the last follow-up $(0.36 \pm 0.094$ vs. $0.35 \pm 0.101)(P>0.05)$. The mean change VAS score at 1 month and last follow-up in the surgery group were significantly lower than those in the chemotherapy group $(5.13 \pm 0.971$ and $4.52 \pm 0.960$ vs. $4.30 \pm 0.952$ and $3.09 \pm 1.180)(P<0.001)$. The mean change ODI at 1 month in the surgery group and chemotherapy group were $0.53 \pm 0.156$ and $0.45 \pm 0.146(P<0.05)$, and mean change ODI at the last follow-up in the two groups were $0.36 \pm 0.143$ and $0.39 \pm 0.149(P>0.05)$ (Table 1).

The rates of 3-year mortality in the two groups were $7.7 \%, 19.2 \%$, and $42.3 \%$ and $1.8 \%, 21.4 \%$, and $41.1 \%$, respectively $(P>0.05)$. Moreover, the analysis of the cause of death in patients in both groups revealed that the number of patients who developed a pulmonary infection in the chemotherapy group $(n=10)$ was significantly more than that in the surgery group $(n=3)(P<0.05)$. The number of patients who developed an activity disorder in the surgery group (4 patients) was significantly less than that in the chemotherapy group (13 patients) $(P<0.05)$; however, no significant difference was observed in the OS between the two groups (surgery group $41.98 \pm 22.168$, chemotherapy group $42.91 \pm 21.312)(P>0.05)$.

The cohort of 108 patients was divided into groups according to age, ISS staging, fracture quantity, and fracture segments. The OS of patients who underwent surgery and chemotherapy was analyzed by univariate analysis, and no significant difference was observed $(P>0.05)$ (Table 2$)$.

Multivariate analysis of all data revealed a high correlation between ISS staging and OS, and ISS staging was the only independent risk factor of OS. The OS of patients in the ISS stage III was significantly lower than that in ISS stages I and II $(P<0.001)$ (Table 3 , Fig. 3).

In addition, all patients in the surgery group underwent surgery successfully; five patients developed complications such as bone cement leakage. The intraspinal leakage of the filling materials occurred in three patients, and paravertebral leakage of filling materials occurred in two patients; however, none of the patients displayed any obvious neurological symptoms. One patient developed lower extremity paralysis after surgery, and MRI revealed that the spinal canal was compressed by a local tumor (Fig. 4). In terms of comprehensive treatment satisfaction, patients who respond "much better" in the surgery group were higher than those in the chemotherapy group $(65.4 \%$ vs. $17.9 \%)(P<0.05)$ (Table 4$)$.

\section{Discussion}

$\mathrm{MM}$ is often associated with multiple vertebral fractures, and with the progression of the disease, the pathological 
Table 1 Basic information of 108 MM patients with vertebral pathological fracture (single factor analysis)

\begin{tabular}{|c|c|c|c|}
\hline Characteristic & $\begin{array}{l}\text { Surgery value } \\
N(\%) \text { or [SD] }\end{array}$ & $\begin{array}{l}\text { Chemotherapy value } \\
N(\%) \text { or }[S D]\end{array}$ & $P$ value \\
\hline Age & $60.81[8.841]$ & 58.14 [8.225] & 0.108 \\
\hline Gender & & & 0.248 \\
\hline Male & $23(44.2 \%)$ & 31 (55.4\%) & \\
\hline Female & 2955.8\%) & 25 (44.6\%) & \\
\hline ISS staging & & & 0.529 \\
\hline ISS-I & $8(15.4 \%)$ & $9(16.1 \%)$ & \\
\hline ISS-II & 22 (42.3\%) & $18(32.1 \%)$ & \\
\hline ISS-III & $22(42.3 \%)$ & 29 (51.8\%) & \\
\hline Fracture quantity & & & 0.376 \\
\hline 1 & 30 (57.6\%) & 25 (44.6\%) & \\
\hline 2 & 11 (21.2\%) & 17 (30.4\%) & \\
\hline$\geq 3$ & $11(21.2 \%)$ & $14(25.0 \%)$ & \\
\hline Fracture location & & & 0.327 \\
\hline $\begin{array}{l}\text { Cervical } \\
\text { vertebra }\end{array}$ & $0(0.0 \%)$ & $0(0.0 \%)$ & \\
\hline $\begin{array}{l}\text { Thoracic } \\
\text { vertebra }\end{array}$ & 18 (34.6\%) & 24 (42.9\%) & \\
\hline $\begin{array}{l}\text { Lumbar } \\
\text { vertebra }\end{array}$ & 24 (46.2\%) & $18(32.1 \%)$ & \\
\hline Short segment & 10 (19.2\%) & $14(25.0 \%)$ & \\
\hline $\begin{array}{l}\text { Stem cell } \\
\text { transplantation }\end{array}$ & $9(17.3 \%)$ & $18(32.1 \%)$ & 0.075 \\
\hline VAS initial & 7.79 [0.637] & 7.86 [0.903] & 0.651 \\
\hline \multicolumn{4}{|l|}{ VAS post-treated } \\
\hline 1 month & $2.65[0.683]$ & 3.55 [0.893] & 0.000 \\
\hline $\begin{array}{l}\text { Mean change } \\
\text { at } 1 \text { month }\end{array}$ & $5.13[0.971]$ & 4.30 [0.952] & 0.00 \\
\hline Last follow-up & $3.27[0.744]$ & 4.77 [1.279] & 0.000 \\
\hline $\begin{array}{l}\text { Mean change } \\
\text { at last follow-up }\end{array}$ & $4.52[0.960]$ & 3.09 [1.180] & 0.000 \\
\hline ODI initial & $0.72[0.127]$ & $0.74[0.149]$ & 0.381 \\
\hline \multicolumn{4}{|l|}{ ODI post-treated } \\
\hline 1 month & $0.19[0.072]$ & $0.29[0.116]$ & 0.000 \\
\hline $\begin{array}{l}\text { Mean change } \\
\text { at } 1 \text { month }\end{array}$ & $0.53[0.156]$ & $0.45[0.146]$ & 0.009 \\
\hline Last follow-up & $0.36[0.094]$ & 0.35 [0.101] & 0.719 \\
\hline $\begin{array}{l}\text { Mean change } \\
\text { at last follow-up }\end{array}$ & $0.36[0.143]$ & 0.39 [0.149] & 0.284 \\
\hline Activity disorder & $4(7.7 \%)$ & $13(23.2 \%)$ & 0.027 \\
\hline $\begin{array}{l}\text { Overall survival } \\
\text { (month) }\end{array}$ & $41.98[22.168]$ & $42.91[21.312]$ & 0.825 \\
\hline \multicolumn{4}{|l|}{ Mortality rate } \\
\hline 1 year & $4(7.7 \%)$ & $1(1.8 \%)$ & 0.144 \\
\hline 2 years & 10 (19.2\%) & 12 (21.4\%) & 0.777 \\
\hline 3 years & 22 (42.3\%) & 23 (41.1\%) & 0.896 \\
\hline Cause of death & $\begin{array}{l}3 \text { people died of pneumonia (13.6\%), } 18 \text { people died of } \\
\text { disease progression }(81.8 \%), 1 \text { person died of hemorrhage } \\
\text { of the digestive tract }(4.5 \%)\end{array}$ & $\begin{array}{l}10 \text { people died of pneumonia (43.5\%), } 13 \text { people died } \\
\text { of disease progression (56.5\%) }\end{array}$ & 0.027 \\
\hline
\end{tabular}




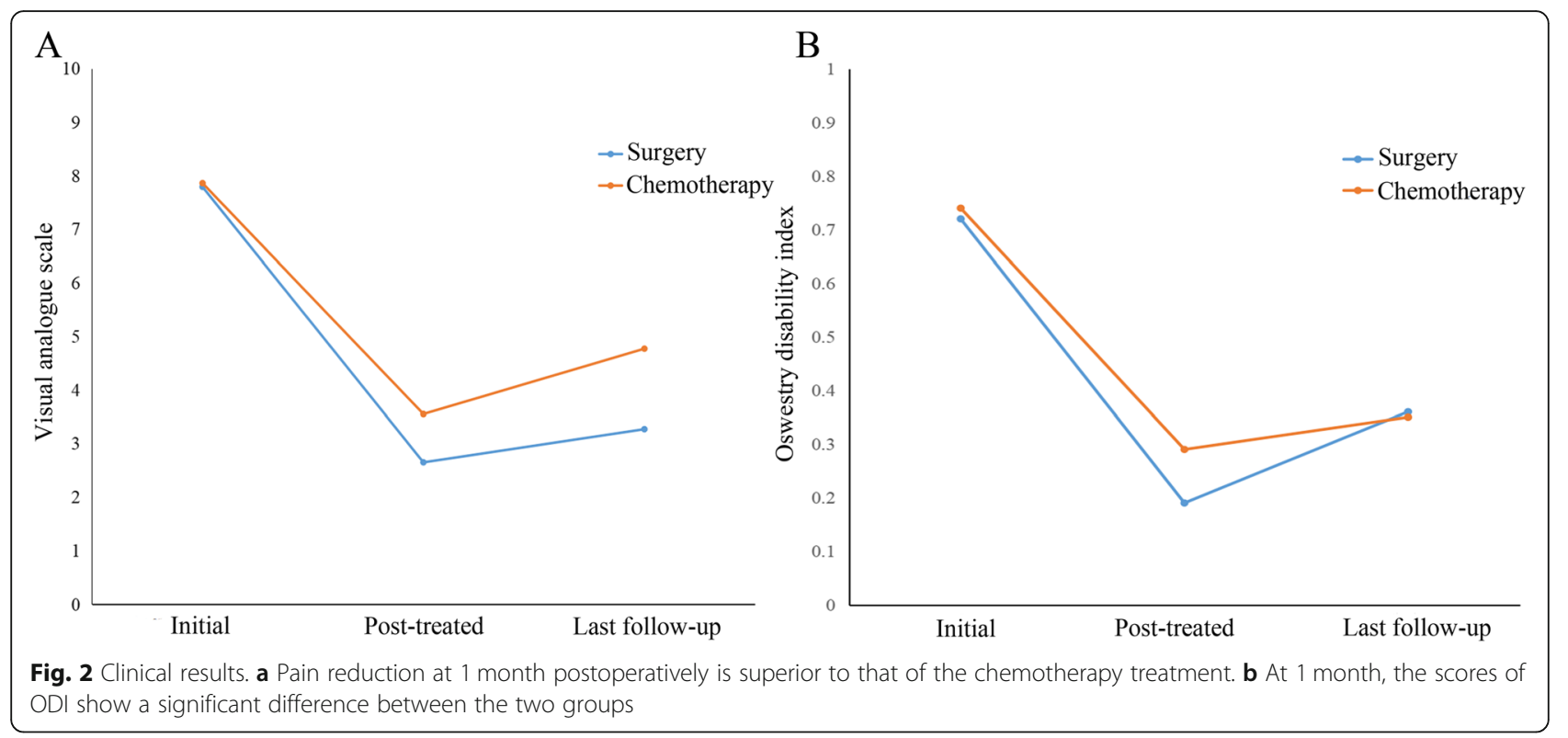

fracture could occur easily. The role of surgery in the management of myeloma-related spinal involvement is controversial. The intraspinal-occupying lesions occurred in patients might develop spinal cord compression symptoms or paraplegia. Presently, the multidisciplinary treatment is accepted as the primary treatment for MM $[9,10]$. However, for the surgical treatment, there are several key issues, including the efficacy of the treatment requires consideration before selecting the approach. Some studies [11-13] suggested that when patients presented a vertebral fracture accompanied by neurological symptoms, surgical treatment was effective in relieving pain, maintaining vertebral

Table 2 Comparison of OS in MM patients who received surgery and Chemotherapy in different groups (Univariate analysis)

\begin{tabular}{|c|c|c|c|}
\hline \multirow[t]{2}{*}{ Characteristic } & \multicolumn{2}{|c|}{ Overall survival (months) [SD] } & \multirow{2}{*}{$\begin{array}{l}P- \\
\text { value }\end{array}$} \\
\hline & Surgery & Chemotherapy & \\
\hline \multicolumn{4}{|l|}{ Age } \\
\hline$<60$-year-old & $40.25[23.055]$ & 38.61 [18.858] & 0.809 \\
\hline$>60$-year-old & $44.17[25.482]$ & 38.88 [22.193] & 0.526 \\
\hline \multicolumn{4}{|l|}{ ISS staging } \\
\hline । & $50.75[22.257]$ & $65.56[19.014]$ & 0.160 \\
\hline$\|$ & $53.55[20.907]$ & $49.39[16.776]$ & 0.499 \\
\hline III & $27.23[13.921]$ & $32.62[16.753]$ & 0.227 \\
\hline \multicolumn{4}{|l|}{ Fracture quantity } \\
\hline 1 & $37.94[23.231]$ & $40.80[21.348]$ & 0.721 \\
\hline$\geq 2$ & $46.71[24.816]$ & $37.42[19.478]$ & 0.187 \\
\hline \multicolumn{4}{|l|}{ Fracture segment } \\
\hline Single segment & $42.41[25.356]$ & 37.36 [19.827] & 0.413 \\
\hline Short-segment & $42.00[20.100]$ & $42.18[21.009]$ & 0.986 \\
\hline
\end{tabular}

volume stabilization, improving the quality of life, and reducing the rate of mortality. Moreover, when a tumor constricts the vertebral canal, an immediate surgical removal is essential to relieve the compression of the vertebral canal. Previous studies [14-16] speculated that chemotherapy or radiotherapy alone could achieve the corresponding treatment effect. Strikingly, Cai [17] reviewed $30 \mathrm{MM}$ patients with spinal metastasis undergone internal fixation, and the pain and neurological function of the patients were found to be improved

Table 3 Multivariate Cox regression analysis of risk factors affecting the survival time of MM patients

\begin{tabular}{llll}
\hline Characteristic & $P$-value & HR & $95 \% \mathrm{Cl}$ \\
\hline Age & 0.156 & 1.020 & $0.992-1.049$ \\
Gender & 0.142 & 0.669 & $0.391-1.145$ \\
ISS staging & & & \\
I & 0.000 & 0.164 & $0.068-0.397$ \\
II & 0.000 & 0.314 & $0.166-0.593$ \\
III & 1 & - & - \\
Fracture location & & & \\
$\quad$ Thoracic vertebra & 0.515 & 1.280 & $0.609-2.690$ \\
$\quad$ Lumbar vertebra & 0.661 & 1.194 & $0.541-2.634$ \\
$\quad$ Short-segment & 1 & - & - \\
Fracture quantity & & & \\
$\quad 1$ & 0.981 & 1.008 & $0.505-2.014$ \\
2 & 0.900 & 1.043 & $0.539-2.020$ \\
$\quad$ 23 & 1 & - & - \\
Stem cell transplantation & 0.771 & 0.914 & $0.499-1.674$ \\
Activity disorder & 0.505 & 0.797 & $0.410-1.553$ \\
Surgery & 0.595 & 0.863 & $0.500-1.488$ \\
\hline
\end{tabular}




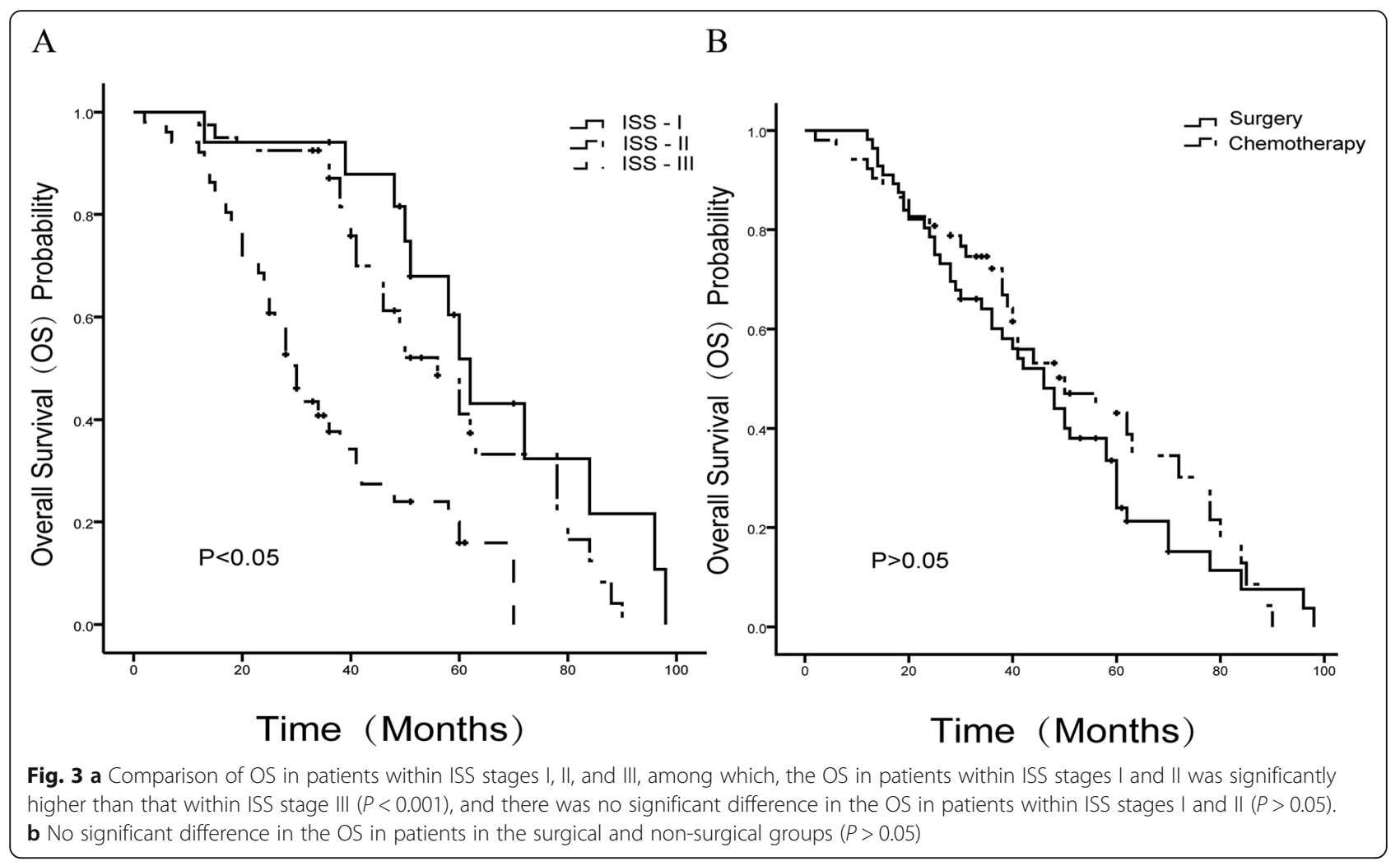

post-surgery. The study postulated that internal fixation was efficient in the treatment of MM patients with spinal instability and neurological dysfunction. Zhang [18] analyzed $36 \mathrm{MM}$ patients with vertebral canal invasion in a retrospective study and found that surgery improved the neurological symptoms of such patients. Furthermore, the early diagnosis of vertebral canal invasion seemed to be critical for patients with MM. Audat [19] who reviewed 14 MM patients who underwent vertebroplasty/kyphoplasty found that adding vertebral augmentation to conventional

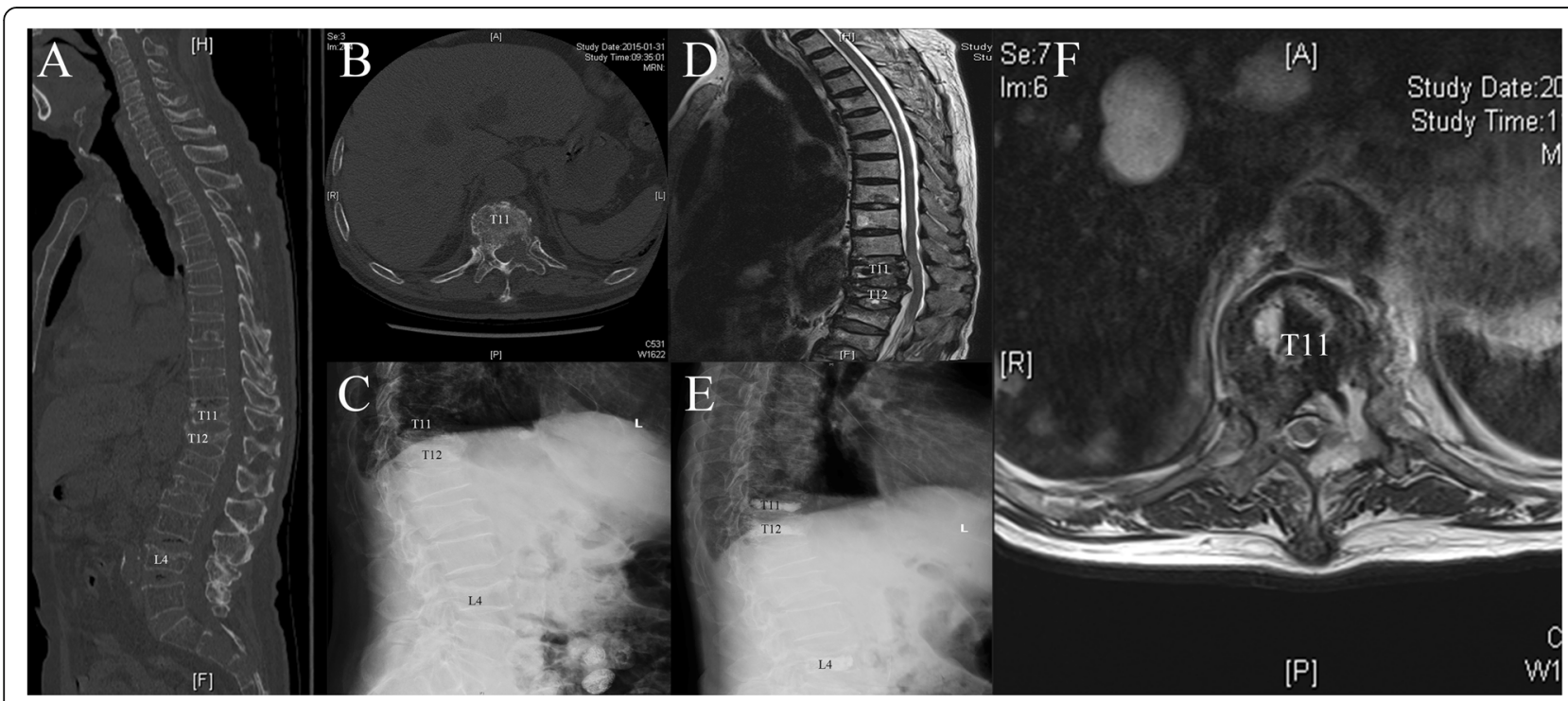

Fig. 4 Images from one patient who developed lower extremity paralysis after surgery. a-c Patient with multiple myeloma with a pathological fracture of T12/T11/L4. CT scan showed that T11/12/L4 vertebral body osteolytic destruction, no spinal canal compression. e Postoperative X-ray plain film scan indicated that the bone cement were implanted successfully. $\mathbf{d}, \mathbf{f}$ MRI revealed soft tissue formation in T11 vertebral body and left pedicle, and paraspinal and costal thoracic joints 
Table 4 Analysis of comprehensive satisfaction of 108 patients after treatment (Chi-square test)

\begin{tabular}{llll}
\hline Response & $\begin{array}{l}\text { Surgery Value } \\
N(\%)\end{array}$ & $\begin{array}{l}\text { Chemotherapy } \\
\text { Value N (\%) }\end{array}$ & $P$-value \\
\hline Very much better & $34(65.4 \%)$ & $10(17.9 \%)$ & 0.000 \\
Much better & $10(19.2 \%)$ & $31(55.4 \%)$ & 0.000 \\
A little better & $5(9.6 \%)$ & $14(25.0 \%)$ & 0.065 \\
No change & $2(3.8 \%)$ & $1(1.8 \%)$ & - \\
Worse & $1(1.9 \%)$ & $0(0.0)$ & - \\
\hline
\end{tabular}

therapy improves multiple myeloma patients' quality of life, but did not affect the mortality rate.

In the case of small trauma, easy operation and high safety led to an increased usage of the minimally invasive surgery in the treatment of osteolytic tumor of the spine with an excellent curative effect $[4,20]$. Ha [21] followed up 27 patients with MM, who had undergone bone cement treatment and demonstrated rapid pain relief post-surgery. Julka [22] performed PKP surgery on 32 MM patients with a compression fracture of vertebral body but without nervous dysfunction. The study found that the pain was significantly improved and vertebral height was essentially restored after surgery, thereby designating it as a safe and effective method for the treatment of MM with a vertebral compression fracture. Kasperk [23] reviewed 73 patients with MM who were subjected to PKP surgery, radiotherapy, and systemic therapy alone; among these patients, the pain in the surgery group was relieved 2 years post-surgery as compared to the other two groups. Moreover, the pain-related activity disorders and the risk of refracture were significantly decreased. Mendoza [24] analyzed the cancer-related symptoms of 79 patients with MM, who underwent PKP/PVP, and found that when the patient's pain was relieved, the anxiety, depression, and cancer-related symptoms were mitigated. The study also speculated that surgery was valuable in improving the overall well-being of the patients harboring the tumor.

For surgical treatment in $\mathrm{MM}$, there were two main concerns: whether surgical treatment could improve the quality of life in patients and whether it could impact the mortality rate of patients with MM. Therefore, single factor analysis was performed to assess $108 \mathrm{MM}$ patients with vertebral pathological fracture; the pain of patients in the surgery group was found to be relieved $(P<0.001)$. The number of patients who developed activity disorder in the surgical group was significantly less than that in the non-surgical group $(P<0.05)$, and the incidence of surgical complications was low. However, PKP/PVP did not prolong the OS in patients with MM according to the statistical results. In addition, the analysis of the cause of death in the two groups showed that the probability of pulmonary infection in the non-surgical group was significantly higher than that in the surgical group $(P=$ 0.027). Furthermore, we proposed that pain relief in the non-surgical group was not distinct, which in turn, affected the daily activities and functional exercises in patients and increased the risk of pulmonary infection. Pneumonia and deep venous thrombosis of the lower limb were the leading causes of death in elderly individuals. When patients with MM suffered from pneumonia or poor nutritional status, they could not receive any chemotherapy; however, after patients underwent surgery, the incidence of pneumonia could be reduced, which also laid the foundation for an uninterrupted follow-up treatment. Nevertheless, the indirect effect of surgery cannot be ignored as it is crucial for the multidisciplinary treatment of MM.

Moreover, after all factors related to survival time were analyzed by multivariate analysis, age, gender, surgery, stem cell transplantation, fracture segment, fracture quantity, and the ability of activity, except ISS staging, were not found to be independent risk factors for OS in patients with MM. The OS of patients in ISS stage III was significantly less than that in ISS stages I and II $(P<0.001)$, which was in agreement with the results of the study by Amelot [7]. Moreover, a total of 108 patients were divided into groups according to their age, ISS staging, fracture quantity, and fracture segment, and single factor analysis was performed to evaluate the OS of patients with and without surgery in different groups; however, no significant difference was found in the OS of patients with and without surgery $(P>0.05)$.

According to the above results, PKP/PVP did not affect the rate of mortality and OS of MM patients in different ISS stages; the location and quantity of fractures neither increased the risk of surgery nor affected the OS in patients. However, after the patients underwent surgery, rapid relief of pain was experienced, and routine life activities were improved. Moreover, the incidence rate of pneumonia was reduced due to prolonged bed rest, following which, the MM patients recovered rapidly and could undergo the next stage of chemotherapy or radiotherapy for the overall treatment.

Nonetheless, this study presented some limitations. Firstly, chemotherapy and radiotherapy programs were not considered as the risk factors for MM survival time. Since the patients diagnosed with MM from 2007 to 2013 were enrolled in this study, the time span of the survey was prolonged. Furthermore, with continual development of the chemotherapeutic program of MM, that for different patients might be varied. Secondly, unlike other spinal malignant tumors, $M M$ was a hematological malignancy. Patients might have also suffered from the pathological fractures of other sites and secondary organ damage to vital organs, such as the heart, liver, and kidney that might affect the prognosis of 
patients with MM. The purpose of this study was to evaluate the efficacy and prognosis of minimally invasive surgery for $\mathrm{MM}$, and only a few cases of the secondary organ damage were noted; therefore, the impact on the survival time was not analyzed.

\section{Conclusion}

Based on the above results, we concluded that PKP/PVP in $\mathrm{MM}$ patients with vertebral pathological fracture was effective in relieving pain. In addition, it reduced the incidence of complications related to bed rest, which in turn, significantly improved the quality of life in patients. Moreover, the rate of mortality and overall survival time in patients was not affected.

\section{Acknowledgements}

We wish to thank Dr. Lihong-Li and Dr. Wenming-Chen, of Beijing Chao-Yang hospital Hematology Dept, for them help in statistical analysis and processing.

\section{Funding}

There is no funding source.

\section{Availability of data and materials}

The datasets during and/or analysed during the current study are available from the corresponding author on reasonable request.

\section{Authors' contributions}

$X C Y / Z Y X$ is the primary author and contributed in drafting and revising the manuscript. ZYX contributed to the data collection and drafting of the manuscript. XCY contributed to the data analysis and interpretation. XRD/ ZYX contributed to the conception of the article and manuscript revision. All authors read and approved the final manuscript

\section{Ethics approval and consent to participate}

Beijing Chao-yang Hospital Human Research Ethics Committee classifies this as a retrospective audit and, as such, does not require ethics submission/approval nor consent to participate.

\section{Consent for publication}

Beijing Chao-yang Hospital Human Research Ethics Committee classifies this as a retrospective audit and, as such, does not require consent to publish.

\section{Competing interests}

The authors declare that they have no competing interests.

\section{Publisher's Note}

Springer Nature remains neutral with regard to jurisdictional claims in published maps and institutional affiliations.

Received: 13 September 2018 Accepted: 24 January 2019 Published online: 11 February 2019

\section{References}

1. Rajkumar SV, Dimopoulos MA, Palumbo A, Blade J, Merlini G, Mateos MV Kumar S, Hillengass J, Kastritis E, Richardson P, Landgren O, Paiva B, Dispenzieri A, Weiss B, LeLeu X, Zweegman S, Lonial S, Rosinol L, Zamagni E, Jagannath S, Sezer O, Kristinsson SY, Caers J, Usmani SZ, Lahuerta JJ, Johnsen HE, Beksac M, Cavo M, Goldschmidt H, Terpos E, Kyle RA, Anderson KC, Durie BG, Miguel JF. International Myeloma Working Group updated criteria for the diagnosis of multiple myeloma. Lancet Oncol. 2014;15:e538-48.

2. Tosi P. Diagnosis and treatment of bone disease in multiple myeloma: spotlight on spinal involvement. Scientifica (Cairo). 2013;2013:104546.

3. Kim S, Kim Y, Ha K, Lee J, Lee J. Surgical roles for spinal involvement of hematological malignancies. J Korean Neurosurg Soc. 2017;60(5):534-9.
4. Health Quality Ontario. Vertebral augmentation involving vertebroplasty or kyphoplasty for cancer-related vertebral compression fractures: a systematic review. Ont Health Technol Assess Ser. 2016;16(11):1-202.

5. Yao X-C, Du W-S, Du X-R, Luo H, Xu Z-Y. Cortical bone destruction-the major factor causing bone cement leakage after kyphoplasty in multiple myeloma. Int J Clin Exp Med. 2017;10:16506-12.

6. Greipp PR, Miguel JS, Durie BG, et al. International staging system for multiple myeloma. J Clin Oncol. 2005;23:3412e3420.

7. Amelot A, Moles A, Cristini J, Salaud C, Touzeau C, Hamel O, Bord E, Buffenoir K. Predictors of survival in patients with surgical spine multiple myeloma metastases. Surg Oncol. 2016;25:178-83.

8. Greipp PR, San Miguel J, Durie BG, Crowley JJ, Barlogie B, Blade J, Boccadoro M, Child JA, Avet-Loiseau H, Kyle RA, Lahuerta JJ, Ludwig H, Morgan G, Powles R, Shimizu K, Shustik C, Sonneveld P, Tosi P, Turesson I, Westin J. International staging system for multiple myeloma. J Clin Oncol. 2005;23:3412-20.

9. Miller JA, Balagamwala EH, Chao ST, Emch T, Suh JH, Djemil T, Angelov L. Spine stereotactic radiosurgery for the treatment of multiple myeloma. J Neurosurg Spine. 2017;26:282-90

10. Terpos E, Morgan G, Dimopoulos MA, Drake MT, Lentzsch S, Raje N, Sezer O, Garcia-Sanz R, Shimizu K, Turesson I, Reiman T, Jurczyszyn A, Merlini G, Spencer A, Leleu X, Cavo M, Munshi N, Rajkumar SV, Durie BG, Roodman GD. International Myeloma Working Group recommendations for the treatment of multiple myeloma-related bone disease. J Clin Oncol. 2013;31:2347-57.

11. Surgeon's Committee of the Chinese Myeloma Working Group of the International Myeloma F. Consensus on surgical management of myeloma bone disease. Orthop Surg. 2016:8:263-9.

12. Zadnik PL, Goodwin CR, Karami KJ, Mehta Al, Amin AG, Groves ML, Wolinsky JP, Witham TF, Bydon A, Gokaslan ZL, Sciubba DM. Outcomes following surgical intervention for impending and gross instability caused by multiple myeloma in the spinal column. J Neurosurg Spine. 2015;22:301-9.

13. Tancioni F, Lorenzetti M, Navarria P, Nozza A, Castagna L, Gaetani P, Aimar E, Levi D, Di leva A, Pisano P, Santoro A, Scorsetti M. Rodriguez y Baena R. Vertebroplasty for pain relief and spinal stabilization in multiple myeloma. Neurol Sci. 2010;31:151-7.

14. Denaro V, Denaro L, Albo E, Papapietro N, Piccioli A, Di Martino A. Surgical management of spinal fractures and neurological involvement in patients with myeloma. Injury. 2016:47(Suppl 4):S49-53.

15. Rao G, Ha CS, Chakrabarti I, Feiz-Erfan I, Mendel E, Rhines LD. Multiple myeloma of the cervical spine: treatment strategies for pain and spinal instability. J Neurosurg Spine. 2006;5:140-5.

16. Basic-kes V, Basic-Jukic N, Kes P, Demarin V, Labar B. Neurologic sequelae of bone changes in multiple myeloma and its therapy. Acta Med Croatica. 2002;56:103-7.

17. Cai W, Yan W, Huang Q, Huang W, Yin H, Xiao J. Surgery for plasma cell neoplasia patients with spinal instability or neurological impairment caused by spinal lesions as the first clinical manifestation. Eur Spine J. 2015;24:1761-7.

18. Zhang J, Zhong Y. Clinical analysis of 36 multiple myeloma patients with extramedullary plasmacytoma invasion of the spinal canal. Hematol Oncol. 2015;33:75-9.

19. Audat ZA, Hajyousef MH, Fawareh MD, Alawneh KM, Odat MA, Barbarawi MM, Alomari AA, Jahmani RA, Khatatbeh MA, Assmairan MA. Comparison if the addition of multilevel vertebral augmentation to conventional therapy will improve the outcome of patients with multiple myeloma. Scoliosis Spinal Disord. 2016;11(1)

20. Garcia-Maroto R, Garcia-Coiradas J, Milano G, Cebrian JL, Marco F, LopezDuran L. Safety and efficacy of kyphoplasty in the treatment of tumoral disease of the spine. Rev Esp Cir Ortop Traumatol. 2015;59:406-12.

21. Ha KY, Min CK, Seo JY, Kim YH, Ahn JH, Hyun NM, Kim YC. Bone cement augmentation procedures for spinal pathologic fractures by multiple myeloma. J Korean Med Sci. 2015:30:88-94.

22. Julka A, Tolhurst SR, Srinivasan RC, Graziano GP. Functional outcomes and height restoration for patients with multiple myeloma-related osteolytic vertebral compression fractures treated with kyphoplasty. J Spinal Disord Tech. 2014;27:342-6.

23. Kasperk C, Haas A, Hillengass J, Weiss C, Neben K, Goldschmidt H, Sommer U, Nawroth P, Meeder PJ, Wiedenhofer B, Schmidmaier G, Tanner M, Neuhof D, Noldge G, Grafe IA. Kyphoplasty in patients with multiple myeloma a retrospective comparative pilot study. J Surg Oncol. 2012;105:679-86.

24. Mendoza TR, Koyyalagunta D, Burton AW, Thomas SK, Phan MH, Giralt SA, Shah JJ, Cleeland CS. Changes in pain and other symptoms in patients with painful multiple myeloma-related vertebral fracture treated with kyphoplasty or vertebroplasty. J Pain. 2012;13:564-70. 